\title{
Kepadatan Populasi dan Sebaran Cacing Tanah di Lahan Sawah Sistem Pertanian Organik, Semi Organik dan Konvensinal
}

\author{
Population Density of the Earthworm and Its Distribution in Rice Fields Managed with \\ Organic, Semi Organic and Conventional Farming Systems
}

\author{
Ea Kosman Anwar*, RDM. Simanungkalit, Edi Santoso, dan Sukristiyonubowo \\ Balai Penelitian Tanah Jl. Ir. H. Juanda No. 98 Bogor 16123 \\ E-mail: eakaanwar@yahoo.com *Penulis untuk korespondensi
}

\begin{abstract}
Earthworm is one of the soil macrofauna, which consumes organic matter for body growth and life. Therefore the earthworm can be soil organic status and soil fertility indicator. On the other hand, at present, the organic farming system is developing and positively accepted by people as yield consumer, and yield price is higher than conventional yield price. The experimen to study the earthworm population rate and spread methode was conducted in 2008 planting season, in West Java, with RBD (Randomized Block Design). Three farming system as treatment i.e Organic farming, Semi organic and Conventional farming system and six location as replication. The result showed that Semi organic farming system is the most earthworm population rate and the earthworm distribution is random model.
\end{abstract}

Key words: Earthworm, lowland, organic farming system

\begin{abstract}
Abstrak
Cacing tanah merupakan salah satu makrofauna tanah yang memakan bahan organik untuk keperluan hidup dan pertumbuhannya. Dengan demikian cacing tanah bisa digunakan sebagai indikator status kandungan bahan organik dan kesuburan tanah. Di lain pihak saat ini pertanian organik berkembang dan mendapat respons positif di masyarakat dengan harga produksi pertanian organik yang relatif lebih tinggi dibanding produksi pertanian konvensinal. Telah dilakukan penelitian untuk mengetahui populasi dan sebaran cacing tanah pada lahan sawah sistem pertanian Organik, Semi Organik dan Konvensional pada musim tanam 2008, pada 6 lokasi sebagai ulangan. Hasil penelitian menunjukkan sistem pertanian Semi Organik menunjukkan populasi cacing tanah tertinggi dengan model sebaran random.
\end{abstract}

Kata kunci: Cacing tanah, sawah, sistem pertanian organik

Diterima: 20 April 2009, disetujui: 14 Desember 2009

\section{Pendahuluan}

Cacing tanah merupakan makrofauna yang hidup menyebar dari lahan kering kapasitas lapang sampai lahan jenuh air, dari dataran rendah sampai dataran tinggi dan memakan bahan organik untuk kebutuhan hidup dan berkembang biak. Dengan demikian keberadaan cacing tanah bisa digunakan sebagai salah satu indikator status kandungan bahan organik sekaligus tingkat kesuburan tanah. (Suin, 2003).

Cacing tanah sangat penting dalam proses dekomposisi bahan organik tanah. Bersamasama hewan tanah lain, cacing tanah ikut berperan dalam siklus biogeokimia. Cacing tanah memakan serasah daun dan materi tumbuhan yang mati lainnya, dengan demikian materi tersebut terurai dan hancur. Cacing tanah juga berperan dalam mengubah rasio $\mathrm{C} / \mathrm{N}$ bahan organik, dan mengubah hara tidak tersedia menjadi tersedia setelah dikeluarkan berupa kotoran (casting). Selain itu cacing tanah juga memberikan sumbangan nitrogen pada tanah yang berasal dari epitel usus yang dikeluarkan bersama casting, dan juga hasil ekskresi dari nefridianya Herman's Adventure, 2004; Schwert, 1990). Hasil perombakan bahan organik oleh cacing tanah yang tercampur 
kotoran lainnya dikenal dengan nama vermikompos (Parmelee et al., 1990).

Saat ini isu sistem pertanian organik berkembang di masyarakat petani dan mendapat respons positif dari konsumen pengguna hasilhasil pertanian sehingga hasil-hasil pertanian organik mempunyai harga relatif lebih tinggi (harga beras organik Rp. $8000 . \mathrm{Kg}^{-1}$ ) dibanding hasil pertanian nonorganik (konvensional) (harga beras biasa Rp. $4000 \mathrm{Kg}^{-1}$ ) (Usman, 2008), dengan harapan hasil pertanian organik lebih aman dikonsumsi karena tidak mengandung pestisida dibandingkan dengan hasil pertanian konvensional.

Kegiatan pertanian konvensional yang hanya berorientasi untuk memaksimalkan hasil dengan mengandalkan bahan kimia pertanian berupa pupuk dan biosida mengakibatkan penurunan kualitas hasil dan lingkungan. Hal ini terlihat antara lain dari kadar hara dalam tanah tidak seimbang, keanekaragaman hayati tanah menurun, biomassa fauna tanah menurun, dan fluktuasi populasi jenis fauna dominan meningkat (Hill, 2004). Kemunduran sifat fisik, kimia dan biologis tanah pada sebagian besar sistem pertanian konvensional dalam jangka panjang merupakan salah satu masalah yang serius bagi keberlanjutan usaha tani (Dumarezq dan Geens, 2001; Kabirun, 2004).

Tujuan penelitian ini adalah untuk mempelajari tingkat kepadatan populasi dan sebaran cacing tanah sebagai indikator hayati tingkat kesuburan tanah pada lahan sawah sistem pertanian Organik, Semi organik, dan Konvensional.

\section{Metode Penelitian}

Penelitian dilakukan pada MT. 2008, di Kabupaten Cianjur yang merupakan salah satu sentra produksi dan lumbung padi di Jawa Barat, pada lahan sawah petani pelaku sistem pertanian Organik, Semi organik, dan Konvensional, dipilih petani yang sudah melakukan sistem tersebut minimal dua tahun. Digunakan Rancangan Acak Kelompok (RAK). Sistem pertanian Organik (asupan hara 8-10 t.ha ${ }^{-1}$ kompos jerami), Semi organik (asupan hara 4-5 t.ha ${ }^{-1}$ kompos jerami + $100 \mathrm{~kg}$ Urea $+50 \mathrm{Kg}$ TSP) dan Konvensional $(200 \mathrm{Kg}$ Urea $+100 \mathrm{Kg}$ TSP) sebagai perlakuan dan 6 lokasi sebagai ulangan pada hamparan jenis tanah Inceptisols, yaitu satu lokasi di Cianjur kota dan lima lokasi di Kecamatan Cikalong Kulon, Jawa Barat yaitu: Desa Benda 1, Desa Benda 2, Sukagalih 1, Sukagalih 2 dan Desa Waru Doyong. Sampel tanah untuk analisis hara dan kepadatan populasi cacing tanah diambil secara komposit mengacu kepada Metode Analisis Biologi Tanah (Anwar, 2007). Cacing tanah dikumpulkan dari sampel tanah (tanpa diidentifikasi sampai jenis) dengan metode 'hand sorting' sedangkan analisis hara $\mathrm{C}$ dan $\mathrm{N}$ dilakukan di laboratorium kimia Balai Penelitian Tanah.

Kepadatan populasi dihitung dengan (Suin, 2003):

\section{$\mathbf{K}=\underline{\text { Jumlah Individu }}$ Jumah contoh/Volume}

$\mathrm{K}=$ Kepadatan Populasi

Sebaran (distribusi) dihitung dengan Koefisien Dispersi (Suin, 2003):

$$
\begin{aligned}
& \mathbf{K d}=\mathbf{X}^{2} /(\mathbf{N}-\mathbf{1}) \\
\text { Di mana: } & \mathrm{X}^{2}=\mathrm{S}^{2}(\mathrm{~N}-1): \mathrm{X} \\
\mathrm{Kd} & =\text { Koefisien dispersi } \\
\mathrm{S}^{2} & =\text { Varian } \\
\mathrm{N} & =\text { Jumlah Contoh } \\
\mathrm{X} & =\text { rata-rata }
\end{aligned}
$$

Bila:

$\mathrm{Kd}=$ mendekati 1 berarti distribusinya secara acak

$\mathrm{Kd}=0$ berarti distribusinya beraturan

$\mathrm{Kd}>1$ berarti distribusinya berkelompok.

\section{Hasil dan Pembahasan}

\section{Kepadatan Cacing Tanah}

Cacing tanah yang teridentifikasi dari jenis Pheretima javanica, jenis cacing ini banyak ditemukan di P. Jawa, habitat yang disenanginya tanah lembab, panjang tubuh 108-173 mm, dengan diameter 4,1-5,3 $\mathrm{mm}$, warna bagian ventral coklat muda sampai keputih-putihan. Hasil "hand sorting" diperoleh di Desa Warudoyong menunjukan kepadatan populasi cacing tanah tertinggi dibanding dengan lokasi lainnya dan tidak berbeda nyata dengan Cianjur kota yang memperlihatkan kepadatan populasi cacing tanah dan kandungan $\mathrm{C}$ dan $\mathrm{N}$ lebih tinggi dari desa-desa dari Cikalong kulon. Karbon organik tanah pada semua lokasi 
penelitian menunjukan diatas $2.0 \%$ s.d. $3.24 \%$ dan $\mathrm{N}$ antara $0,21 \%$ s.d. $0,32 \%$, ini berarti lokasilokasi tersebut mengandung $\mathrm{C}$ organik dan hara N sedang (Balai Penelitian Tanah, 2005), untuk mempertahankan produltivitas tanah pada lahanlahan tersebut memerlukan penambahan bahan organik dan pemberian $\mathrm{N}$ (Tabel 1).

Nilai $\mathrm{C} / \mathrm{N}$ semua lokasi menunjukan nilai sedang, berarti pelapukan bahan organik sudah cukup lanjut dan tidak akan membahayakan tanaman karena terjadi mobilisasi hara oleh mikroba dekomposer (Tabel 1).

Rata-rata kepadatan populasi cacing tanah tertinggi diperoleh pada sistem pertanian Semi organik yaitu 6,6 ekor setiap liter tanah lumpur, sedangkan kandungan $\mathrm{C}, \mathrm{N}$ dan $\mathrm{C} / \mathrm{N}$ relatif tidak berbeda antara sistem pertanian organik, semi organik dan konvensional. Hal ini membuktikan apabila asumsi kehadiran cacing tanah sebagai indikator kesuburan tanah, sistem pertanian Semi organik merupakan sistem pertanian yang dapat meningkatkan kesuburan lahan. Ini terjadi karena tanah pada lahan-lahan sistem pertanian Semi organik selain penambahan bahan organik diberikan juga pupuk anorganik setengah dosis anjuran, sehingga kebutuhan hara bagi mikro dan makro organisme tanah dan tanaman terpenuhi. Fauna tanah termasuk cacing tanah menduduki rantai makanan paling atas pada piramida rantai makanan di dalam ekologi mikro di dalam tanah (Suin, 2003). Sementara itu, sistem pertanian organik atau konvensional penambahan hara masing-masing hanya berasal dari introduksi bahan organik dan bahan kimia saja (Tabel 2).

Pada Tabel 3, nilai matrik korelasi tertinggi terjadi antara $\mathrm{C}$ dan $\mathrm{N}$ yaitu 0.9233 , kemudian korelasi antara cacing dan $\mathrm{C} / \mathrm{N}$ dan antara $\mathrm{C}$ dan $\mathrm{C} / \mathrm{N}$ dengan nilai korelasi di atas 0.51. Nilai korelasi menunjukkan keeratan hubungan keberadaan tiap-tiap komponen. Data tersebut memperlihatkan bahwa keberadaan unsur $\mathrm{N}$ yang dilepas (dirilis) dari bahan yang sama yaitu bahan organik (jerami atau lainnya) yang diberikan ke dalam tanah relatif setara (sebanding) dengan C yang dilepas, perbandingan ini akan sama sesuai dalam ikatan kompleknya. Keeratan cacing tanah dengan $\mathrm{C} / \mathrm{N}$ relatif tinggi, disebabkan cacing tanah memakan serasah bahan organik dan mengolahnya menjadi lebih halus, atau cacing tanah mendekomposisikan bahan organik "mentah' yang mengandung $\mathrm{C} / \mathrm{N}$ tinggi diolah menjadi bahan organik yang "matang" yang mengandung $\mathrm{C} / \mathrm{N}$ lebih rendah dan dilanjutkan mineralisasi oleh mikroorganisme lainnya seperti bakteri dan jamur. Demikian juga keeratan $\mathrm{C}$ dengan $\mathrm{C} / \mathrm{N}$. Pelapukan (dekomposisi) oleh fauna dan mikroorganisme tanah akan meluruhkan $\mathrm{C}$ dan $\mathrm{N}$ yang terikat dalam ikatan komplek di dalam bahan organik menjadi tersedia bagi tanaman, namun unsur $\mathrm{N}$ lebih mobil dan mudah hilang oleh folatilisasi, aktivitas urease dan denitrifikasi dan unsur $\mathrm{C}$ lebih stabil berada di dalam tanah dengan demikian keeratan $\mathrm{C}$ dengan $\mathrm{C} / \mathrm{N}$ lebih tinggi dibandingkan $\mathrm{N}$.

\section{Sebaran Cacing Tanah}

Dari Tabel 4 terlihat nilai koefisien distribusi cacing tanah $(\mathrm{Kd})$ pada semua model sistem pertanian kurang dari 1 dan mendekati 0 , sistem pertanian Semi organik mempunyai nilai koefisien distribusi paling kecil yaitu 0,15 , kemudian sistem pertanian Organik 0,26 dan Konvensional 0,29. Data tersebut menunjukan distribusi cacing tanah berarti beraturan, semakin mendekati nol (0) semakin erat tingkat keberaturannya. Ini menunjukan cacing tanah hidup sesuai dengan ketersediaan bahan makanan dan hara tersedia, pada sistem pertanian semi organik, bahan organik (kompos) sebagai bahan makanan dan hara (dari Urea dan TSP) tersedia, tingkat keeratannya lebih tinggi dibandingkan sistem pertanian Organik dan Konvensional, dan sistem pertanian Organik tingkat keeratannya lebih tinggi dibandingkan pertanian Konvensional. Hal ini membuktikan cacing tanah hidup tergantung pada tingkat kesuburan tanah di mana bahan organik sebagai sumber bahan makanan dan hara tersedia bagi cacing tanah. 
Tabel 1. Rata-rata kepadatan populasi cacing tanah dan kandungan $\mathrm{C}, \mathrm{N}$ organik dan $\mathrm{C} / \mathrm{N}$ pada tiap lokasi.

\begin{tabular}{lcccc}
\hline \hline \multirow{2}{*}{ Lokasi } & \multicolumn{3}{c}{ Hasil analisis } \\
\cline { 2 - 5 } & Kepadatan Cacing (ekor.1lt ${ }^{-1}$ tanah) & C (\%) & N (\%) & C/N \\
\hline \hline 1. Cianjur Kota & $5.7 \mathrm{ab}$ & $3.24 \mathrm{a}$ & $0.32 \mathrm{a}$ & $10.7 \mathrm{a}$ \\
2. Desa Benda 1 & $4.0 \mathrm{~b}$ & $2.15 \mathrm{~b}$ & $0.21 \mathrm{a}$ & $10.3 \mathrm{a}$ \\
3. Desa Benda 2 & $2.3 \mathrm{~b}$ & $2.12 \mathrm{c}$ & $0.22 \mathrm{~b}$ & $9.7 \mathrm{~b}$ \\
4. Desa Sukagalih 1 & $4.0 \mathrm{~b}$ & $2.46 \mathrm{~b}$ & $0.27 \mathrm{a}$ & $9.3 \mathrm{c}$ \\
5. Desa Sukagalih 2 & $3.7 \mathrm{~b}$ & $2.15 \mathrm{~b}$ & $0.22 \mathrm{~b}$ & $9.7 \mathrm{~b}$ \\
6. Desa Warudoyong & $8.0 \mathrm{a}$ & $2.35 \mathrm{~b}$ & $0.27 \mathrm{a}$ & $9.0 \mathrm{c}$ \\
\hline \hline \multicolumn{1}{c}{ K.K (\%) } & 12,3 & 3,87 & 4,21 & $1 \%, 06$ \\
\hline \hline
\end{tabular}

Tabel 2. Rata-rata kepadatan populasi cacing tanah dan kandungan $\mathrm{C}, \mathrm{N}$ organik dan $\mathrm{C} / \mathrm{N}$ pada tiap sistem pertanian.

\begin{tabular}{lcccc}
\hline \hline \multirow{2}{*}{ Sistem Pertanian } & \multicolumn{3}{c}{ Hasil analisis } \\
\cline { 2 - 5 } & Kepadatan Cacing (ekor.1It ${ }^{-1}$ tanah) & C (\%) & N (\%) & C/N \\
\hline \hline Pert. Organik & $3.8 \mathrm{~b}$ & $2.5 \mathrm{a}$ & $0.30 \mathrm{a}$ & $9.17 \mathrm{~b}$ \\
Pert. Semi Organik & $6.6 \mathrm{a}$ & $2.5 \mathrm{a}$ & $0.30 \mathrm{a}$ & $10.17 \mathrm{a}$ \\
Pert. Konvensional & $3.5 \mathrm{~b}$ & $2.5 \mathrm{a}$ & $0.30 \mathrm{a}$ & $10.0 \mathrm{a}$ \\
\hline \hline KK $(\%)$ & 19,5 & 8,11 & 7,5 & 2,9 \\
\hline \hline
\end{tabular}

Tabel 3. Matrik korelasi antara kepadatan populasi cacing dengan $\mathrm{C}$ dan $\mathrm{N}$.

\begin{tabular}{lccc}
\hline \hline & Cacing & $\mathbf{C} / \mathbf{N}$ & $\mathbf{N}$ \\
\hline \hline Cacing & - & - & - \\
$\mathrm{C} / \mathrm{N}$ & 0.5866 & - & - \\
$\mathrm{N}$ & -0.4842 & 0.1482 & - \\
$\mathrm{C}$ & -0.2251 & 0.5125 & 0.9233 \\
\hline \hline
\end{tabular}

Tabel 4. Komponen sebaran cacing tanah pada tiap-tiap sitem pertanian.

\begin{tabular}{cccccc}
\hline \hline Sistem Pertanian & $\mathbf{X}($ rata-rata) & $\mathbf{S}^{\mathbf{2}}$ & $\mathbf{N - 1}$ & $\mathbf{X}^{\mathbf{2}}$ & $\mathbf{K d}$ \\
\hline \hline Organik & 3.8 & 1 & 5 & 1,32 & 0,26 \\
Semi Organik & 6,5 & 1 & 5 & 0.77 & 0,15 \\
Konvensional & 3,5 & 1 & 5 & 1,43 & 0,29 \\
\hline \hline
\end{tabular}

\section{Simpulan dan Saran}

\section{Simpulan}

Pertanian semi organik menunjukan tingkat populasi cacing tanah paling tinggi dibandingkan dengan sistem pertanian organik dan konvensional. Pada semua sistem pertanian mempunyai sebaran cacing tanah beraturan. Kepadatan populasi cacing tanah dipengaruhi oleh kematangan bahan organik tanah.

\section{Saran}

Untuk mempertahankan produktivitas tanah pada lahan-lahan tersebut memerlukan penambahan bahan organik dan pemberian $\mathrm{N}$. Dengan tersedianya sumber energi dari bahan organik dan $\mathrm{N}$ metabolisme biota tanah akan tetap terjadi, proses delomposisi dan mineralisasi tetap berlangsung dan ketersediaan hara bagi biota dan tanaman terjamin.

\section{Ucapan Terima Kasih}

Ucapan terima kasih disampaikan kepada bapak H. Usman sebagai Ketua Gabungan Kelompok Tani Kecamatan Kota Cianjur dan Gabungan Petani Organik Kabupaten Cianjur atas segala kebaikan dan bantuannya sehingga penelitian ini bisa selesai dengan baik.

\section{Daftar Pustaka}

Anwar, E.K. 2007. Analisis Kelimpahan Populasi dan Karakteristik Cacing Tanah. In: Rasti S., Edi, H. dan Simanungkalit, R.D.M. (Eds). Metode Analisis Biologi Tanah. Hal. 269-282. Balai Besar Litbang Sumberdaya Lahan Pertanian. Badan Penelitian dan Pengembangan Pertanian, Departemen Pertanian.

Balai Penelitian Tanah. 2005. Analisis Kimia Tanah, Tanaman, Air dan Pupuk. Edisi Pertama. Badan Penelitian dan Pengembangan Pertanian Departemen Pertanian. 
Dumaresq, D. dan Greene, R. 2001. Soil Structure, Fungi, Fauna and Phosphorus in Sustainable Cropping Systems. RIRDC Pub. No. 01/130.

Herman's Adventure. www.urbanext.uiuc.edu/worms. 09/06/2004.

Hill, B.S. 2004. Soil Fauna and Agriculture: Past Findings and Future Priorities. EAP Pub. 25. 8pgs. http://eap.megill.ca/Publications/eap-head.htm. 04/21/2007.

Kabirun, S. 2004. Peranan Mikoriza Arbuskular pada Pertanian Berkelanjutan. Pidato Pengukuhan Jabatan Guru Besar dalam Ilmu Mikrobiologi pada Fakultas Pertanian Universitas Gadjah Mada Yogyakarta.

Parmelee, R.W., Beare, M.H., Cheng, W., Hendrix, P.F., Rider, S.J., Crossley, D.A.Jr. dan Coleman, D.C. 1990. Earthworm and Enchytraeids in Conventional and No-tillage Agroecosystems: A Biocide Approach to Asses Their Role in Organic Matter Breakdown. Biol. Fertil. Soils, 10: $1-10$.
Schwert, D.P. 1990. Oligochaeta: Lumbricidae. In: Dindal, D.L. (Eds.). Soil Biology Guide. Pp.341-356. A Wiley-Interscience Publication, John Wiley and Sons. New York. Chichaster. Brisbone. Toronto. Singapore.

Suin, N.M. 2003. Ekologi Hewan Tanah. Penerbit Bumi Aksara Jakarta Bekerjasama dengan Pusat Antar Univesitas Ilmu Hayati Institut Teknologi Bandung.

Usman. 2008. Ketua Gabungan Kelompok Tani Kecamatan Kota Cianjur, Gabungan Petani Organik Kabupaten Cianjur (personal approach). 